\title{
IOT BASED LPG LEAKAGE ALERTING AND ACCIDENT PREVENTION SYSTEM
}

\author{
K. Sai Krishna Veni, K. Satya Veni, K. Paviyhra, K. Prasanthi \\ Department Of ECE \\ VSM College Of Engineering, \\ Ramachandrapuram, AP - 533255 \\ P Ravi Shankar \\ Asst Professor, Department Of ECE \\ VSM College Of Engineering, \\ Ramachandrapuram, AP - 533255
}

\begin{abstract}
Now a days the major problem of gas leakage occurred in industries sector and in residential locations etc.., This project is to propose a system that can detect, alert and block the electrical power supply. In this project we are using a gas sensor which has high sensitivity to propane and butane gases through which the LPG and it is consist of a GSM module that can alert the user through sms. This project presents a security system that prevents fire accidents in residential and the industrial areas due to LPG leakages to implement this we are adding relays to switch off the power supply from the mains when the sensor senses the leakage of gas so that it prevents the gas explosion and minimize the risk of fire accidents.
\end{abstract}

\section{Keywords: GSM module, LPG}

\section{INTRODUCTION}

In our India every human must be used to LPG [Liquid Petroleum Gas] for Cooking Purpose. Now a days the use of LPG is rapidly increases. This means the number of people's are using this fuel. But some problems are raised by using these type of gases.

one of the major problems by using LPG is failure in detection of leakage of gas so that it cause desperate deficit in our life. We all are know that more fire accidents are occurs in our world due to the failure detection of leakage of LPG gas, so here is our project IOT BASED LPG LEAKAGE ALERTING AND ACCIDENT PREVENTION SYSTEM By using this we can easily detect the leakage of LPG Gas and resulting in preventing the fire accidents.

Normally gas leakage can be occur from the gas cylinders and also from gas pipeline. Physically LPG leakage is detected using gas sensor and also alert the user by using GSM module and Buzzer. The Buzzer is used to alert the user when it detects the gas leak with a beep sound and the another alerting system is GSM module. It alerts the user through sms. The relay plays a major role it continuously monitor if any gas leakage from the cylinder. Relay is used to shutdown the power immediately in dangerous situations.

If it detect the leakage from the cylinder it shut down the power from the mains by using relay, and will also Alert the user regarding gas leak. The LPG detection system is very small and also used in hotels and residential locations. So that IOT based LPG leakage alerting and accident preventing system is very helpful to our society to prevent the accidents.

\section{BLOCK DIAGRAM \& HARDWARE COMPONENTS}

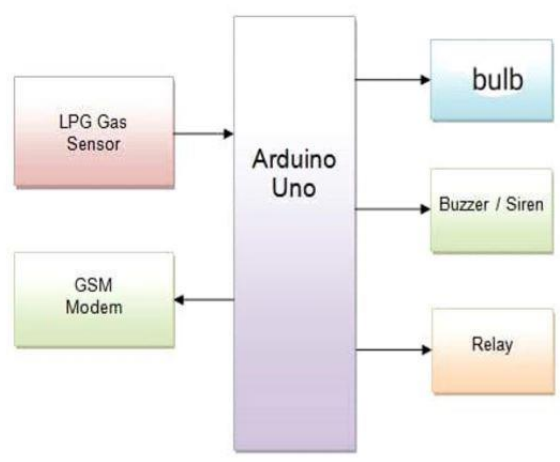

Fig: Block Diagram

The IOT Based LPG leakage alerting and accident preventing system. In this project arduino uno is the main working component of the entire project. Arduino board consists of both digital and analog pins. The gas sensor is connected to the analog pin of arduino and sense the gas leakage. The digital pins are connected with GSM module, Buzzer and Relay.

The gas sensor senses the gas leakage it alerts the GSM module, relay and buzzer. GSM module and Buzzer are used to alert the user and by 


\section{International Journal of Engineering Applied Sciences and Technology, 2020 \\ Vol. 5, Issue 1, ISSN No. 2455-2143, Pages 379-381 \\ Published Online May 2020 in IJEAST (http://www.ijeast.com)}

using relay we can shut down the power from the mains. So by using thus project we create accident free life.

\section{Arduino Uno:}

The arduino uno is a one of the micro controller band based on ATMEGA 328. This arduino controller board consist of number of input, output, gnd and power supply pins and arduino board is easily connected to pc by using usb cable. Nearly it has 14 digital input/output pins and it has a $16 \mathrm{MHZ}$ resonator, a usb connection, power jack. The arduino is software based project and it has printed circuit board, we can easily interface arduino with other electronic compnonets according to our use and it is also low cost. The arduino board is started at interaction design institute ivera and invented by Massimo Benzi in Italy.It also provide on board storage.

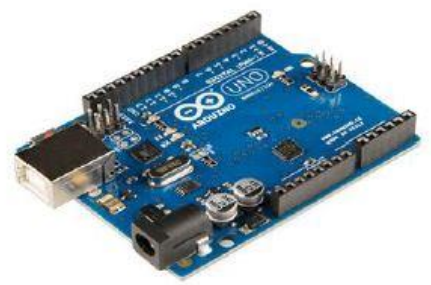

Fig: Arduino Board

\section{MQ-9 Gas Sensor:}

In our market number of gas sensor are available. By using gas sensor we can easily detect the gas leakage. In this project we are using MQ-9 sensor.MQ-9 sensor consist of four pins they are Vcc, Gnd,A0 and D0.MQ-9 sensor is operates at very low voltage like 5v.This MQ-9 sensor sensitive components consist of two components one is heating circuit and the second one is signal output circuit. Mainly in this project it is used to detect the LPG leak because MQ-9 sensor is very sensitive to detect the LPG leak.

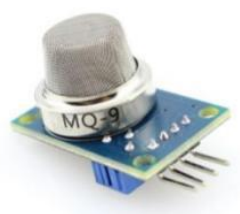

Fig:MQ-9 Sensor

\section{GSM Module:}

GSM means Global System For Mobile communication. In this project we are using GSM Module SIM 900A.It supports dual bands (900/1800MHZ).By using GSM Module we can perform the more functionalities those are alerts the users by sending messages and calling automatic reading and sending of messages and calls by using AT Commands. It operates at $12 \mathrm{v}$ and having $[\mathrm{Tx}, \mathrm{Rx}]$ pins, these pins are used to send and receive messages to the user.SIM 900 is the most popular device in GSM modules. The GSm consist of $+5 \mathrm{v}$, GND,Serial In (Rx or Rxd) and serial out ( $\mathrm{Tx}$ or Txd).

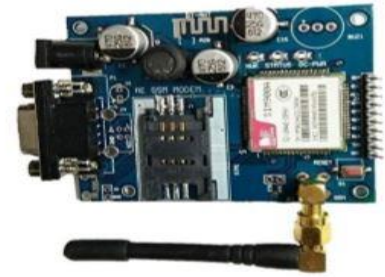

Buzzer:

Fig: GSM Module (SIM 900A)

Buzzer is also called as beeper. It produces the audio signal and buzzer is one of the user alerting system. So the buzzer is mainly used as a security system. The buzzer consist of two types of fundamentals like Active and Passive. It is very small in size, low cost and less weight

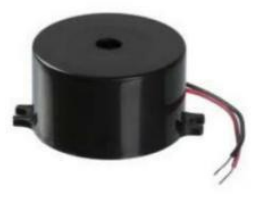

Fig: Buzzer

\section{Relay:}

Relay is an electrically operated switch. By using this relay we can controlling the circuits by a low power signal or one signal. The first relay was used in long distance telegraph circuits as amplifiers after used in logical circuits. This relay consists of 3 Pins those are In, Vcc, Gnd, and it consist of $\mathrm{NO}$ Comm, NC.

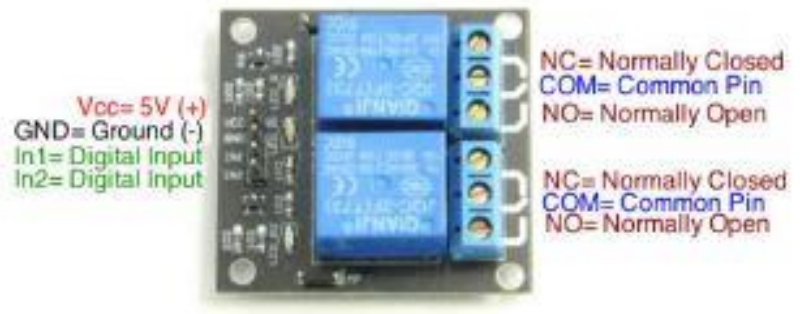

Fig: Relay

\section{CIRCUIT DIAGRAM}

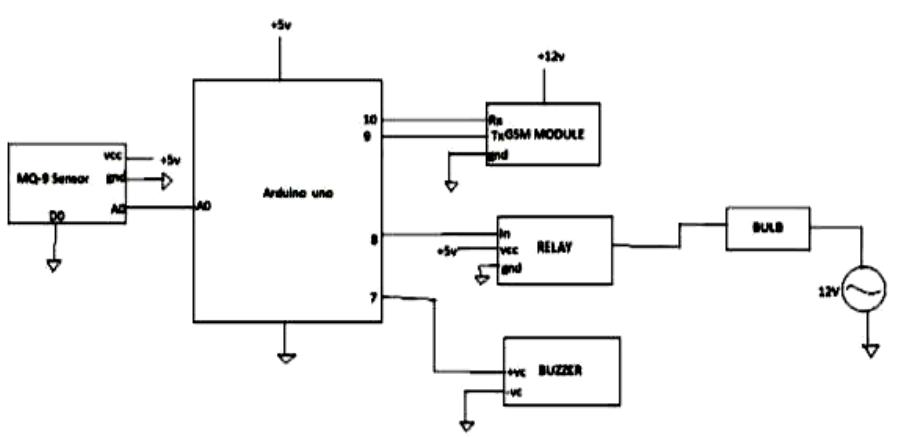

Fig: Circuit Diagram 
In this project we are using 6 components. The arduino is the main important device because it is a arduino based project. The gas sensor A0 pin is connected to the Arduino A0 pin. The gas sensor detects the lekage of gas it will alert the GSM module buzzer and relay through arduino uno. The GSM module $[\mathrm{Tx}, \mathrm{Rx}]$ are connected to arduino $[9,10]$ pins. Buzzer positive pin is connected to the arduino 7 pin.

The relay In pin is connected to the arduino 8 pin. In this project we are using bulb because the gas sensor detect any lekage of gas it automatically shut down the power from mains by using relay. So we can observe that the bulb glows off. The bulb is connected in between the relay and power supply.

\section{APPLICATIONS \& CONCLUSION}

\section{Applications:}

$>$ It is low power consumption and reliable.

$>$ It avoid gas leakages and fire accidents.

$>$ The system is tamper-proof and secure.

$>$ It is low cost and possible to get instantenous results with high accuracy.

$>$ It also detects the alcohol soit is used as alcohol sensor also.

$>$ It is low power consumption so we can use smoke detection and toxic gases by doing some modifications.

$>$ The system enables monitoring of gas lekage in remote locations and there by leads to faster response time in the events of a leakage conditions.

$>$ The complexity of the circuit is very less.

\section{Conclusion:}

So by using IOT Based LPG leakage alerting and accident preventing system we preventing any design caused by gas leakage and useful as a part of safety to avoid the gas leak, that can cause harmful result. Gas leakage leads to serve accidents resulting in material losses and human injuries. By using LPG leakage detection we prevent accidents and save human lives. And this system provides alert information using GSM module and buzzer and also automatic power off by using through relay. This system is very helpful to our society to avoid gas leakage fire accidents.

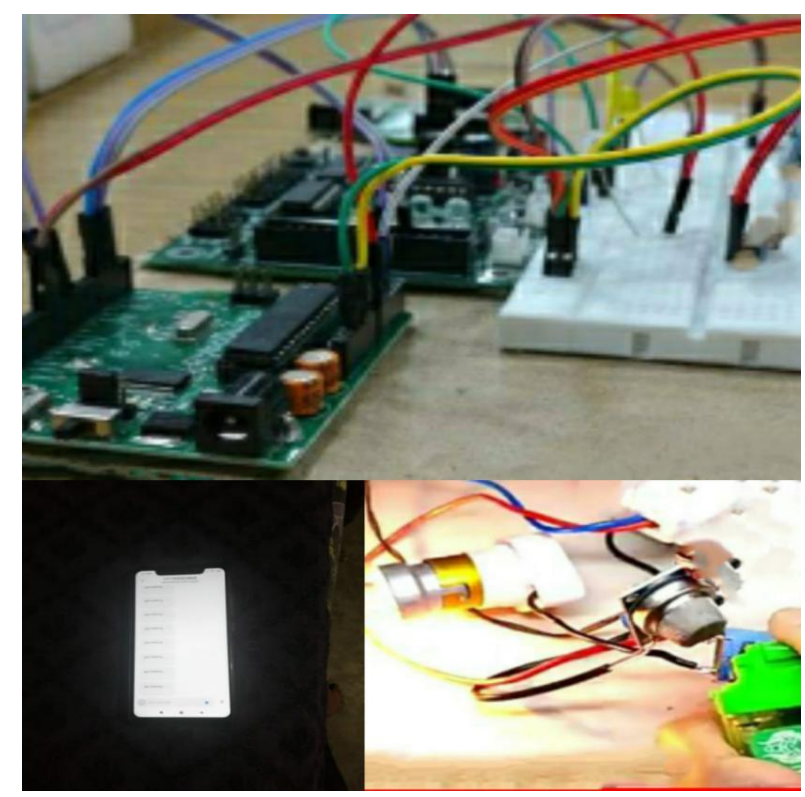

Fig: Working Module

\section{REFERENCE}

1.Selvapriya C, Sathya Prabha S, Abdulrahim M, Aarathi K C, 'LPG Leakage Monitoring and Multilevel Alerting System', International Journal Of Engineering Sciences \& Research Technology, ISSN: 2277-9655,2(11):November,2013.

2.AravindhaBeliyara, 'GSM Based Gas Leakage Detection System Using Arduino',International Journal of Engineering Technology Science and Research, ISSN 2394-3386, Volume 4, Issue 10, October 2017.

3.T.Soundarya, J.V.Anchitaalagammai, G. Deepa Priya, S.S. KArthick Kumar, 'C-Leakage: Cylinder LPG Gas Leakage Detection for Home Safety', IOSR Journal of Electronics and Communication Engineering (IOSR-JECE) e-ISSN: 2278-2834,pISSN:2278-8735.Volume 9, Issue 1, Ver. VI, pp.5358,Feb.2014.

4. S. K. K. T. K. R. R.Naresh Nuke, P.Siva Nagendra Reddy,"Arduino based LPG gas monitoring, automatic cylinder booking with alertsystem," IOSR Journal of Electronics and Communication Engineering (IOSR-JECE), Vol. 11, 2016.

5. S. K. D. P. S. R. . Abid Khan, Neju K. Prince, "GSM based automatic LPG ordering system with leakage alert," IJRET, Vol. 3, 2014. 